\title{
O desenvolvimento da educação básica no Amapá de 1991 a 2003: da retórica à prática
}

\author{
Antonia Deusa Sá \\ ORCID: 0000-0002-5371-124X \\ José Francisco de Carvalho Ferreira ${ }^{1}$ \\ ORCID: 0000-0001-8266-166X
}

\section{Resumo}

Este artigo apresenta uma análise do desenvolvimento da educação básica no Amapá, desde a sua estadualização de fato - em 1991, quando tomou posse o primeiro governador eleito - até 2003, último ano previsto para a vigência do Plano Decenal de Educação do Estado. Com quase um quarto da população de analfabetos e um quadro de contínuo aumento populacional, uma das grandes demandas, no início da década, era a de melhores índices na educação básica. Neste encalço, são analisadas a elaboração e a implementação das principais propostas do poder público estadual para o desenvolvimento da educação básica no estado e mensurados os avanços destas propostas. A pesquisa é quali-quantitativa e, metodologicamente, interagem os métodos histórico e estatístico, mediante os quais se buscou reconstruir um processo para obter generalizações históricas, indo diretamente às fontes primárias, complementando com a análise estatística de cinco indicadores educacionais. Os resultados assinalam que no Amapá, assim como no Brasil, era comum, na década de 1990, o discurso oficial sobre a erradicação do analfabetismo e a oferta de educação pública de qualidade com gestão democrática. Contudo, os avanços alcançados foram insuficientes e não significaram, necessariamente, resultados qualitativos, dados os altos índices de reprovação e evasão escolar. 0 poder público do Amapá planejou e determinou os rumos da educação básica pública, no entanto, os resultados não são decorrentes de processos democraticamente participativos, tampouco alteraram, significativamente, o status quo da estrutura social do Amapá.

\section{Palavras-chave}

Políticas de educação - Educação básica - Desenvolvimento - Plano Decenal de Educação - Amapá.

1- Universidade Federal do Amapá, Macapá, AP, Brasil. Contatos: sa-antonia@hotmail.com; zfcofer@gmail.com. 


\section{The development of basic education in Amapá from 1991 to 2003: from rhetoric to action*}

\section{Abstract}

This article presents an analysis of the development of basic education in Amapá since its real inception as a state of the Federation - in 1991, when the first state governorelect took office - until 2003, the last year foreseen for the Decennial Education Plan of the State. With almost a quarter of the population illiterate and a context of continuous population growth, one of the great demands at the beginning of the decade was for better indices in basic education. In this regard, it analyses the elaboration and implementation of the main proposals of the state public power for the development of basic education in the state, and measures the advances of these proposals. The research is quantitative and, methodologically, interacts with historical and statistical methods in order to rebuild a process and obtain historical generalizations, going directly to the primary sources, complementing with the statistical analysis of five educational indicators. The outcomes indicate that in Amapá, as in Brazil, in the 1990s, the official speech on eradicating illiteracy and providing good quality public education with democratic management was common. However, the progress achieved was insufficient and did not necessarily mean qualitative outcomes, given the high rates of school failure and dropout. The public power of Amapá planned and determined the direction of public basic education, however, the results do not derive from a democratically participatory process, nor did they significantly alter the status quo of the social structure of Amapá.

\section{Keywords}

Education policies - Basic education - Development - Decennial education plan - Amapá.

\section{Introdução}

0 retorno da experiência democrática e a elaboração da Constituição Federal de 1988 (BRASIL, 2012) promoveram uma grande efervescência política no Brasil, na década de 1980, sendo este um período fértil da história brasileira, no que tange à organização da educação (GHIRALDELLI JÚNIOR, 1990; SAVIANI, 2007). Neste período da redemocratização, o Brasil apresentava dados alarmantes de mais de 30\% dos adultos analfabetos e numeroso contingente de crianças e jovens sem acesso à escolarização básica.

Muito embora a conjuntura política tenha propiciado renovação das expectativas de avanços significativos na educação, para Hermida Aveiro (2002), é comum na história brasileira, em períodos de crise econômica e política, realizar reformas constitucionais que implicam em novas leis para a educação, uma vez que estas são indissociáveis. A reformulação das políticas públicas e mesmo uma nova constituição parecem ser a 
consequência comum das crises da superestrutura, sem, no entanto, mudar o status quo da estrutura social total.

Entre os planos e as novas regulações da educação nacional da década de 1990, destacam-se o Plano Decenal de Educação para Todos (PDET), de 1993 (BRASIL; MEC, 1993); a Lei de Diretrizes e Bases (LDB), de 1996 (BRASIL, 2010); o Fundo de Manutenção e Desenvolvimento do Ensino Fundamental e de Valorização do Magistério (Fundef) (BRASIL; MEC, 2004) e o Plano Nacional de Educação (BRASIL, 2001), elaborado na década e aprovado em janeiro de 2001. Na disputa ideológica entre educadores mobilizados e o poder público, para definir os rumos da educação nacional, prevaleceram as propostas do Poder Público (BOLLMANN, 2010; SAVIANI, 2007).

Tomando a conjuntura política da década de 1990 como indicativo de possibilidade de avanços nas políticas públicas de educação de âmbito nível nacional e estadual, este artigo objetivou analisar o desenvolvimento da educação básica no estado do Amapá naquela década. A análise incidiu sobre as ações do poder público concernentes à educação básica pública, e sobre os resultados educacionais quantitativos alcançados na década, tanto na esfera pública quanto na iniciativa privada, demonstrando, assim, o desenvolvimento quantitativo da educação nas duas instâncias.

Como questionamento de partida, procurou-se saber, além da retórica do poder público, o que, de fato, avançou na educação básica, o que permaneceu e possíveis novas configurações da educação no estado amapaense. Metodologicamente, interagiram os métodos histórico e estatístico através dos quais se buscou reconstruir um processo para obter generalizações históricas, indo diretamente aos documentos primários, que relataram o planejamento e a efetivação das políticas de educação, rematando com a análise das sinopses estatísticas da educação básica, de 1991 a 2003, divulgadas pelo Ministério da Educação.

Foram selecionados documentos internos do Executivo estadual com abrangência na década de 1990 e mais três anos da década seguinte, considerados por Gil (1989, p. 51) como documentos de primeira mão, isto é, documentos que "[...] não receberam qualquer tratamento analítico [...]”. Estes apresentaram a descrição das ideias ou retóricas norteadoras da educação pública e, em tese, direcionaram a educação no Amapá: o Plano Decenal de Educação do Estado do Amapá (PDEEA), elaborado durante o governo estadual de Anníbal Barcellos (1991-1994), com previsão de vigência de 1994 a 2003, e o Plano de Desenvolvimento Sustentável do Amapá (PDSA), mais especificamente as Diretrizes Curriculares para o estado do Amapá, elaboradas no governo estadual de João Alberto Capiberibe (1995-2002).

Para a análise dos resultados da educação no recorte temporal de 1991 a 2003, foi seguida a proposição de Coelho $(2016$, p. 80$)$ para a avaliação de políticas públicas, pela qual os indicadores de valor devem ser buscados na literatura teórica e normativa. Para o autor, a avaliação de uma política pública apresenta um julgamento de valor, ou seja, um julgamento sobre a adequação daquilo que foi descrito tendo em conta parâmetros ou critérios determinados por indicadores, sem buscar entender ou descrever relações e mecanismos, nem caracterizar processos. 
Os planejamentos estaduais de educação foram utilizados para embasar a análise descritiva do que foi planejado na educação básica no Amapá, enquanto a análise do que foi efetuado segue os parâmetros dos cinco Indicadores de Qualidade na Educação estabelecidos pela Unicef (Fundo das Nações Unidas para Infância), PNUD (Programa das Nações Unidas para o Desenvolvimento) e INEP Instituto Nacional de Estudos e Pesquisas Educacionais Anísio Teixeira) (BRASIL; INEP; MEC, 2004). Os Indicadores são: número de escolas (públicas e privadas); número de profissionais da educação (e respectiva formação); matrículas; taxas de alfabetização, analfabetismo e conclusão da educação básica; acesso à educação especial e de jovens e adultos. Para verificar os índices de sucesso e insucesso do processo educativo, a educação básica é analisada por rendimento - aprovação, reprovação e evasão.

A análise estatística permitiu avaliar as políticas de educação no estado, no que concerne a alcançar os resultados almejados (COELHO, 2016). Para demonstrar os resultados concernentes ao quantum integral da população em análise, são utilizados os censos demográficos, de 1991 e 2000, do Instituto Brasileiro de Geografia e Estatística (BRASIL; IBGE, 1991, 2000) e os censos escolares do Instituto Nacional de Estudos e Pesquisas Educacionais Anísio Teixeira (Inep), de 1991 a 2003. A análise dos dados permite aferir os avanços ou retrocessos da educação básica e estabelecer comparações entre os índices de educação pública e privada.

Este artigo começa por apresentar o planejamento da educação no Brasil, seguindose a apresentação do planejamento da educação no estado do Amapá, mais especificamente o Plano Decenal da Educação, elaborado no final de 1993, e o Plano de Desenvolvimento Sustentável do Amapá, proposta política do Governo iniciado em 1995, considerando, também, as diretrizes curriculares para o estado do Amapá. Em item subsequente, são apresentados os resultados da educação básica no estado do Amapá, entre 1991 e 2003, trabalhados em gráficos e tabelas do Excel, considerando a alfabetização/analfabetismo, as dinâmicas das escolas públicas e privadas, os profissionais da educação, as matrículas e o rendimento da educação básica. 0 artigo termina com as considerações finais e as referências usadas, documentais e bibliográficas.

\section{O planejamento da educação nacional}

No início da década de 1990, o Ministério da Educação (MEC) declarou que os baixos índices da educação nacional eram interdependentes das condições de vida de grande parte da população brasileira, de fatores como o considerável contingente de crianças e adolescentes pobres nas zonas rurais e a problemática resultante da dinâmica de migração das classes pobres para os centros urbanos (BRASIL; MEC, 1993).

Somam-se a esses fatores os desafios econômicos de um longo período de instabilidade e recessão que produziram e potencializaram altos níveis de desigualdade social e regional, com mais de 39 milhões de pessoas vivendo abaixo da linha de pobreza e com níveis mínimos de oportunidades sociais, como o acesso a serviços de saúde e educação, impossibilitando o exercício da cidadania plena. Essa proposição do MEC indica que o principal problema da educação nacional era estrutural, ou seja, a precariedade da 
educação era resultante das também precárias condições sociais, econômicas e políticas do país (BRASIL; MEC, 1993).

Nesta década de 1990, destacam-se alguns planos e novas regulações com vistas a desenvolver a educação nacional: o Plano Decenal de Educação para Todos (PDET), de 1993 (BRASIL; MEC, 1993); a Lei de Diretrizes e Bases (LDB), de 1996 (BRASIL, 2010); o Fundo de Manutenção e Desenvolvimento do Ensino Fundamental e de Valorização do Magistério (Fundef), instituído pela Lei No 9.424, de 24 de dezembro de 1996, com início em 1997, e o Plano Nacional de Educação, aprovado pela Lei $n^{\circ} 10.172$, de 9 de janeiro de 2001 (BRASIL, 2001). 0 modelo de escola e de educação no país foi objeto de disputa entre os educadores, mobilizados a nível nacional, e o poder público, mas, tanto para a LDB/96 como para o Plano Nacional de Educação de 2001, prevaleceram as propostas do Poder Público (BOLLMANN, 2010; BRASIL, 2001; SAVIANI, 2007).

O PDET, com previsão de vigência de dez anos, a partir de 1993, tinha como objetivo erradicar o analfabetismo e universalizar o ensino fundamental no Brasil. Neste encalço, os entes da Federação foram convidados a pactuar com as metas do plano e a elaborar seus próprios planos decenais, seguindo as premissas nacionais consolidadas na Semana Nacional de Educação para Todos, realizada pelo MEC, em Brasília, de 10 a 14 de maio de 1993. À semelhança dos outros entes da federação, o estado do Amapá se fez presente no evento (BRASIL; MEC, 1993).

O PDET estabelece metas, medidas e instrumentos para enfrentar os obstáculos e propor estratégias para erradicar o analfabetismo e universalizar a educação básica. No entanto, não faz referência a possíveis estratégias políticas de enfrentamento e superação dos desafios socioeconômicos do Brasil, embora destaque que o desenvolvimento da educação é interdependente do desenvolvimento econômico e social do país. Esta interdependência entre modelo de desenvolvimento econômico e desenvolvimento da educação também é ratificada, entres outros, por Furtado (2004), ao propor que o desenvolvimento real deve estar acompanhado de mudanças das estruturas econômicas, políticas, sociais e institucionais do país, mas este não tem sido o modelo brasileiro de desenvolvimento.

Uma das premissas do plano para superar um dos grandes entraves da educação pública - o corporativismo e a política clientelista que permeavam a educação tanto por parte da administração pública quanto dos sindicatos - seria estabelecer instrumentos favoráveis à continuidade e sustentação das políticas educacionais e à gestão dos sistemas e das unidades escolares, independentes das mudanças de governo (BRASIL; MEC, 1993).

Analisando os resultados do plano, Gadotti (2000) verificou que a discussão da educação nacional era cíclica, ou seja, apenas quando aparecem as grandes conferências, reaparece a discussão. Esta descontinuidade pode resultar na perda não apenas do trabalho realizado em função do plano, mas também da discussão e do movimento que o sucedeu em todos os estados brasileiros e resultou nos respectivos planos decenais estaduais.

Gadotti (2000) propôs que o Estado devia ir além da retórica e da assinatura de documentos, devia se articular em nível federal, estadual e municipal para mobilizar a sociedade civil, em especial as escolas, rumo à educação para todos, proposta na Declaração Mundial de Educação para Todos, resultante da Conferência Mundial de Educação Para 
Todos realizada, em 1990, em Jomtien, na Tailândia. Esta proposição também foi reforçada por Saviani (2002).

Considerando-se que o analfabetismo caiu de 25\%, em 1991, para 15\%, em 2000, houve consideráveis avanços quantitativos na educação nacional. Porém, apesar de grande acesso ao ensino fundamental, ${ }^{2}$ a problemática do analfabetismo e das desigualdades sociais e regionais de acesso e êxito na educação básica não foi resolvida, de fato. Carneiro (2012) aponta a precariedade da etapa final da educação básica (o ensino médio), intitulando-a como "o gargalo da educação no Brasil", pois este nível de ensino continuou a apresentar insuficiência de oportunidades de acesso e êxito, mesmo após todas as regulações da educação na década. Todos os planos e leis, até então, tiveram como foco apenas a universalização do ensino fundamental, deixando de fora a educação infantil, o ensino médio, a educação de jovens e adultos e a educação especial.

\section{O planejamento da educação no Amapá}

Em 1991, o Amapá tinha uma população de 289.397 habitantes, com mais de 80\% vivendo na zona urbana. A capital, Macapá, e a cidade vizinha Santana concentravam 80\% da população. No ano 2000, a população do estado era de 477.032 habitantes, representando a maior taxa média geométrica de crescimento anual do Brasil $(5,77)$. Só na população de Macapá e Santana houve um aumento de mais de 144 mil novos habitantes na década, chegando-se ao final desta com apenas 10\% da população amapaense residindo na zona rural (BRASIL; IBGE, 1991; 2000).

0 acelerado crescimento populacional do novo estado foi impulsionado por eventos pontuais como a instalação da Indústria e Comércio de Minérios (ICOMI), em 1953; a implantação do Projeto Jari, em 1968; a estadualização, em 1988; e a implantação da Área de Livre Comércio de Macapá e Santana (ALCMS), em dezembro de 1991. 0 crescimento demográfico e o processo de urbanização desordenada do estado, principalmente de sua capital - Macapá - ocorreu principalmente pela chegada desordenada de imigrantes oriundos do Pará, Maranhão e Ceará. Como consequência deste modelo de crescimento e urbanização, ocorreu um estrangulamento na oferta de emprego e de serviços básicos, como água tratada, saneamento e transporte, pois os investimentos em infraestrutura não cresceram na mesma proporção (ABRANTES, 2014).

No início da década de 1990, o Amapá apresentava o menor índice de desigualdade entre os estados da região Norte, menor que os índices de todas as grandes regiões e menor do que o índice geral do Brasil. No decorrer da década, porém, enquanto Rondônia e Roraima tiveram redução no índice de desigualdade, o Amapá teve aumento para o quinto maior índice entre os estados da região, maior do que os índices das regiões Sul e Sudeste, como demonstrado na Tabela 1, onde se apresenta o Índice de Gini. ${ }^{3}$

2- Embora na Conferência de Jomtien se tenha discutido a universalização da educação básica dos países signatários da Declaração Mundial de Educação para Todos, o Plano Decenal restringiu seu foco à universalização do ensino fundamental (BRASIL; MEC, 1993).

3- "O Índice de Gini [...] é um instrumento para medir o grau de concentração de renda em determinado grupo. Ele aponta a diferença entre os rendimentos dos mais pobres e dos mais ricos", variando entre zero (situação de igualdade) e um (concentração de renda) (WOLFFENBÜTTEL, 2004, p. 80). 
Tabela 1 - Índice de Gini da renda domiciliar per capita do Brasil, regiões e unidades federativas da região Norte em 1991 e 2000

\begin{tabular}{|c|c|c|}
\hline País, regiões e unidades federativas & 1991 & 2000 \\
\hline Brasil & 0,6383 & 0,6460 \\
\hline Região Norte & 0,6257 & 0,6545 \\
\hline Acre & 0,6259 & 0,6477 \\
\hline Amapá & 0,5850 & 0,6318 \\
\hline Amazonas & 0,6282 & 0,6823 \\
\hline Pará & 0,6206 & 0,6512 \\
\hline Rondônia & 0,6155 & 0,6110 \\
\hline Roraima & 0,6216 & 0,6202 \\
\hline Tocantins & 0,6331 & 0,6550 \\
\hline Região Nordeste & 0,6593 & 0,6682 \\
\hline Região Sudeste & 0,5984 & 0,6093 \\
\hline Região Sul & 0,5857 & 0,5893 \\
\hline Região Centro-Oeste & 0,6244 & 0,6420 \\
\hline
\end{tabular}

Fonte: Datasus (BRASIL; MS; DATASUS, 1991, 2000).

Ao analisar a ação do Estado para o desenvolvimento amapaense, Chelala (2008) constata a incapacidade ou a omissão do poder público em amenizar os impactos negativos, diretos ou indiretos, resultantes dos empreendimentos liberais no estado, pois, embora os grandes empreendimentos econômicos na região tenham ocorrido com o aval e auxílio governamental, o fator humano - o povo local e o que chegou em busca de oportunidades - foi, em sua maioria, negligenciado pelo Estado.

Para Chelala (2008), ainda que no Amapá as políticas públicas pudessem ter maior poder de alcance da população, dada a maior magnitude do aparelho estatal amapaense, isto não conduziu a resultados positivos para a população local. No entender do autor, na maioria das vezes, o Estado se mostrou vacilante e ineficaz no que tange ao planejamento e à execução de políticas públicas de compensação dos impactos negativos dos empreendimentos econômicos na região, pois os direitos sociais do povo não foram substantivados.

\section{O Plano Decenal de Educação do Estado do Amapá}

O Plano Decenal de Educação do Estado do Amapá (PDEEA) foi elaborado no final de 1993, seguindo o conclame do MEC e as premissas do PDET, apresentado aos estados e municípios na Semana Nacional de Educação para Todos, realizada em maio de 1993, em Brasília. A secretária de Educação do Amapá, presente no evento, subscreveu o Compromisso Nacional com a Educação para Todos, que estabeleceu critérios e compromissos a serem 
seguidos pelos entes federados para a efetivação do Plano Decenal Nacional em escala estadual e municipal (BRASIL; MEC, 1993; AMAPÁ, 1993).

Nos dias 9, 10 e 11 de novembro de 1993, a Secretaria de Estado de Educação do Amapá (SEED) realizou, em Macapá, o I Fórum Estadual de Educação. Os debates propostos foram analisados pela então Secretária de Educação e uma equipe formada por uma comissão central de oito técnicos educacionais, 29 colaboradores, lotados na SEED, cinco representantes de unidades escolares, ${ }^{4}$ colaboradores de apoio operacional da secretaria, participantes de instituições paraeducacionais, organizações sindicais, representantes de associações de bairros e representantes da Universidade Federal do Amapá. 0 resultado deste trabalho originou o PDEEA, com vigência prevista de janeiro de 1994 a dezembro de 2003 (AMAPÁ, 1993).

O PDEEA apresentava como referências o Plano Decenal (nacional), um documentoproposta de uma política de alfabetização elaborado pela SEED, um documento-proposta para redimensionar o ensino de $2^{\circ} \mathrm{Grau}$, o estatuto do magistério, a Constituição Federal de 1988, a Constituição Estadual do Amapá e a Proposta do Amapá para a nova LDB que seria a culminância do Encontro Técnico Regional sobre a nova LDB, realizado em Belém-PA, no ano de 1989 (AMAPÁ, 1993). Esta variedade de encontros e documentos concernentes à educação no estado corroboraram com a observação de Ferreira (2005) de que na década de 1990 havia, à semelhança do quadro nacional demonstrado por Saviani (2002; 2007), uma euforia no meio educacional amapaense devido à recente autonomia político-administrativa conferida pela Constituição Federal de 1988 (BRASIL, 2012).

Ao explicitar a alta taxa de analfabetismo do estado, mais concentradamente na zona rural, o PDEEA indicava que a baixa renda da maioria da população era a principal causa do problema educacional e social no estado, uma vez que a situação de pobreza terminava por conduzir os jovens escolarizáveis precocemente ao mercado de trabalho como opção de sobrevivência e, consequentemente, provocava o alto índice de evasão e repetência, agravando mais ainda a problemática do desenvolvimento socioeconômico de um estado que era constituído, em grande parte, por jovens (AMAPÁ, 1993).

A educação no estado foi diagnosticada com problemas estruturais e organizacionais, em decorrência de um distanciamento do sistema público dos compromissos político-sociais com a educação. Seguindo a premissa de que a educação é um dos processos responsáveis pelo desenvolvimento socioeconômico de uma sociedade, o plano foi apresentado como uma proposta para reverter o quadro precário da educação no estado do Amapá, o que implicava numa decisão política para operacionalizar as mudanças estruturais no sistema de educação (AMAPÁ, 1993).

0 eixo norteador da política estadual de educação seria

[...] a universalização da educação, através da melhoria da qualidade da ação educativa, ampliação e manutenção da rede física, da gestão democrática, partindo de uma filosofia de trabalho assentada nos princípios de credibilidade dos seus postulantes; de integração nos diversos níveis de competência, sob o ângulo sociopedagógico e administrativo, fundamentado nos aspectos

4- E. E. Augusto Antunes, E. E. José de Anchieta, E. E. Irineu da Gama Paes, E. Comercial Gabriel de Almeida Café e Colégio Amapaense (AMAPÁ, 1993). 
político filosóficos; princípio sociológico da interdependência - onde todos os segmentos da sociedade sejam responsáveis pelo processo educacional; princípio epistemológico da construção do real - significando a conciliação entre o que é possível fazer e o que pode ser feito [...] princípio da legitimidade com a participação da sociedade civil organizada na formulação de políticas, planos e programas educacionais. (AMAPÁ, 1993, p.21).

0 PDEEA propôs sete metas a serem alcançadas em dez anos: expandir e melhorar a infraestrutura física, técnica e organizacional dos sistemas de ensino; reduzir, em 50\%, o índice de evasão e repetência no ensino fundamental, principalmente da $1^{\text {a à }} 5^{\text {a }}$ série; assegurar assistência ao educando através de atenção integral a 30\% das crianças e adolescentes de baixa renda; ampliar, em 50\%, o atendimento ao $2^{\circ}$ grau, com cursos voltados para a realidade local; capacitar, em 100\%, as redes de ensino público; ampliar, em 60\%, o quadro de pessoal técnico e administrativo da rede pública de ensino; aperfeiçoar o sistema de planejamento da educação através de utilização de mecanismos tecnológicos modernos.

0 plano não apresentou o orçamento necessário (nem sua disponibilidade) para a operacionalização das metas e ações propostas e, embora sua previsão de operacionalização fosse para o período de 1994 a 2003, nas eleições de 1994 o governador Barcellos não concorreu à reeleição, foi eleito João Alberto Capiberibe, que assumiu o governo do estado, em janeiro de 1995. Por conseguinte, como informado por alguns técnicos em educação lotados na SEED no ano de elaboração do plano, com o novo governo, os profissionais (em tese) comprometidos com o Plano Decenal (que também ocupavam cargos de expressão política nessa secretaria) foram substituídos e o Plano Decenal proscrito e esquecido.

\section{O plano de desenvolvimento sustentável do Amapá (PDSA)}

Quando assumiu o governo do Amapá, em 1995, João Alberto Capiberibe apresentou como plano de governo o Plano de Desenvolvimento Sustentável do Amapá (PDSA), inspirado nos princípios da Agenda 21. ${ }^{5}$ Para viabilizar as estratégias de desenvolvimento sustentável no estado, foram trazidas equipes técnico-científicas externas para, num primeiro momento, ajudar na elaboração e execução das referidas estratégias e, em um segundo momento, criar uma capacidade local de produção de conhecimento em torno da temática de desenvolvimento com proteção ambiental (AMAPÁ, 1995).

0 governo Capiberibe iniciou, em 1995, atividades dentro da SEED para reestruturar o sistema educacional público, segundo as premissas do PDSA, e consolidar a visão deste por meio do sistema educacional do estado. Um documento interno da SEED, localizado na fase exploratória desta pesquisa, intitulado Diretrizes Curriculares da Educação Escolar

\footnotetext{
5- A Agenda 21 é um documento de quarenta capítulos que emergiu da Conferência das Nações Unidas Sobre Meio Ambiente e Desenvolvimento, realizada no Rio de Janeiro, em 1992, sendo considerada como "[...] um instrumento de planejamento para a construção de sociedades sustentáveis, em diferentes bases geográficas, que concilia métodos de proteção ambiental, justiça social e eficiência econômica." (BRASIL; MMA, 1992).
} 
Básica do Estado do Amapá, contém as informações sobre as ações políticas e institucionais na área de educação pública durante a vigência do PDSA (AMAPÁ, 2002).

\section{Diretrizes curriculares para o estado do Amapá}

Em 1999, a SEED estabeleceu parceria com o Instituto de Estudos Especiais da Pontifícia Universidade Católica de São Paulo, cujos consultores promoveram sucessivas reuniões com os técnicos desta secretaria e oficinas para os demais grupos envolvidos no projeto, com o intuito de apresentar uma proposta curricular para a Rede Estadual de Ensino do Amapá e ajustar a educação pública às premissas do PDSA. Em 2000, foi iniciado um processo de três etapas: a primeira e segunda consistiram na mobilização dos técnicos da SEED sobre os pressupostos teórico-metodológicos, que deveriam nortear a proposta curricular, e a terceira abrangeu professores da rede estadual para discutir "o papel das disciplinas escolares, a prática de ensino e a avaliação” (AMAPÁ, 2002, p.12).

Como resultado deste trabalho, no ano 2000 foram publicados e encaminhados para as escolas quatro livros, sendo eles: $O$ ensino de $1^{a} a 4^{a}$ séries: as disciplinas, as habilidades; $O$ ensino de $5^{a}$ a $8^{a}$ séries e o ensino médio: as disciplinas, as habilidades. Volumes 1 e 2; Educação infantil: um projeto em construção. Em 2001, encerrou-se o trabalho da Pontifícia Universidade Católica de São Paulo, e foram consolidadas as Diretrizes Curriculares da Educação Escolar Básica do Estado do Amapá, que se propunham dar suporte às escolas para iniciar "uma nova fase da educação no Amapá, pautada na sustentabilidade e, portanto, na educação socioambiental, na valorização do saber prévio, na autonomia da escola e na construção da cidadania por aqueles que dela participam” (AMAPÁ, 2002, p. 13).

$\mathrm{Na}$ caracterização da rede estadual de escolas do estado, as diretrizes problematizavam a questão urbano-rural, no que tange aos engessados modelos curricular e pedagógico vigentes, que não corroboravam a ideia de inclusão das diferentes comunidades. Portanto, uma das metas do PDSA, no reordenamento das escolas rurais, urbanas e indígenas, era o de superar o perfil globalizado da escola tradicional e incentivar os povos de cultura mais específica a participarem do processo educativo com direito a manter sua identidade própria. De acordo com a nova proposta, a educação indígena deveria ser ensinada na língua materna e os saberes locais deveriam ser dialogados com os saberes da base nacional comum, com o objetivo de se produzirem conteúdos apropriados para uma educação socioambiental (AMAPÁ, 2002).

Outro ponto de atenção das diretrizes foi o insatisfatório serviço de educação especial, por não constituir um modelo integrador do público especial às atividades regulares educacionais das escolas. Outro ponto crítico indicado foi o nível insatisfatório dos alunos que ingressavam no ensino fundamental II ( $5^{\mathrm{a}}$ a $8^{\mathrm{a}}$ série). Estes, em grande parte, não tinham domínio da linguagem (leitura, interpretação e produção de textos) e apresentavam raciocínio lógico-matemático baixo.

As diretrizes foram estruturadas em três eixos: como é a escola pública no Amapá; como ela deveria ser; quais os papéis dos educadores (profissionais da educação) na consecução de uma educação socioambiental, como princípio para a construção da sociedade 
sustentável, projetada pelo PDSA. Foram apresentadas como uma sistematização formal da experiência fragmentada dos profissionais da educação, às quais foram acrescentados elementos conceituais para sistematizar os diversos temas, dentro de aspectos legais, técnicos, administrativos e pedagógicos.

As diretrizes apresentavam proposições de caráter normativo e inovador e, embora este novo padrão estabelecido para o modelo escolar parecesse paradoxal à ideia de autonomia da escola, reclamavam um caráter democrático, por serem resultantes de um amplo debate com a rede estadual de ensino e estarem em consonância com a identidade política do então governo estadual eleito pelo povo (AMAPÁ, 2002).

Para Moulin (2000), os avanços da educação nos moldes do PDSA podiam ser perceptíveis no programa de alfabetização indígena em sua própria língua e na determinação da língua francesa como primeira língua estrangeira no ensino médio, cujo objetivo seria facilitar as relações do Amapá com a Guiana Francesa. ${ }^{6} 0$ autor destacou que 96\% das crianças do Amapá estavam estudando em boas condições materiais e pedagógicas, e fez um chamado a toda a população amapaense para assumir a responsabilidade de construção do "mundo de amanhã" no modelo sustentável proposto pelo PDSA (MOULIN, 2000, p. 113-114).

Leonelli (2000, p. 214), no entanto, ao fazer uma análise do engajamento dos professores no modelo de educação do PDSA, afirmou que eles apresentavam postura corporativista em relação ao Estado, cujo resultado era "uma atitude pedagógica conservadora em relação à estrutura curricular e uma resistência a inovações pedagógicas e a mudanças de maneira geral”. Esta crítica do autor sobre a postura dos professores, e a prevalência de contratos administrativos para prover professores para regiões mais remotas do estado, podem ser indício de que o projeto das Diretrizes Curriculares não correspondeu, exatamente, ao que se propôs e a educação no Amapá não constituiu plenamente uma ferramenta do PDSA.

\section{Resultados da educação básica no Amapá (1991-2003)}

Os avanços da educação no Amapá foram verificados segundo os cinco Indicadores de Qualidade na Educação (BRASIL; INEP; MEC, 2004) e dispostos em triênios, salvo algum dado ocorrido no intervalo de cada triênio e que mereceu destaque.

\section{A alfabetização (0 analfabetismo)}

Em 2000, da população 409.312 indivíduos residentes no Amapá, acima de 5 anos de idade, 17\% ainda eram analfabetos, índice superior ao nacional $(15,7)$. Se considerados os grupos etários dos 5 aos 9 anos, dos 10 aos 14 anos e dos 15 aos 19 anos, entre as crianças de 5 a 9 anos, enquanto o Brasil apresentou uma leve redução neste índice, no Amapá aumentou de 49,3\% para 54\%, o que aponta para a ausência de soluções eficazes para

6- Em 1996, os governos do Brasil e França assinaram o Acordo de Cooperação Franco-Brasileiro que possibilitou a ampliação do ensino da língua francesa no Amapá. Em 2003, foi inaugurado o Centro Estadual de Língua e Cultura Francesa Danielle Mitterrand, na cidade de Macapá. 
o rápido crescimento demográfico e a maior necessidade de oferta de educação infantil. 0 índice de analfabetismo entre os adolescentes de 10 a 14 anos caiu para 5,4\%, índice inferior ao nacional e o dos 15 a 19 anos foi consideravelmente reduzido, permanecendo abaixo do nacional. No entanto, de forma geral, houve um considerável avanço na década no que tange à alfabetização da população, como se indica na Tabela 2.

Tabela 2 - Índice de analfabetismo no Amapá e no Brasil (1991-2000)

\begin{tabular}{|c|c|c|c|c|c|c|}
\hline \multirow{2}{*}{ Idade } & \multirow{2}{*}{$\begin{array}{c}\text { População AP } \\
-1991\end{array}$} & \multicolumn{2}{|c|}{ Índice de analfabetismo em 1991 (\%) } & \multirow{2}{*}{$\begin{array}{c}\text { População AP } \\
-2000\end{array}$} & \multicolumn{2}{|c|}{ Índice de analfabetismo em 2000 (\%) } \\
\hline & & AP & BR & & AP & BR \\
\hline$>5$ & 243855 & 24 & 25 & 409312 & 17 & 15,7 \\
\hline 5 a 9 & 45170 & 49,3 & 48 & 61320 & 54 & 45,9 \\
\hline 7 a 9 & 26848 & 51,6 & 39,8 & 35491 & 31,3 & 23,8 \\
\hline 10 a 14 & 40641 & 16 & 18 & 58785 & 5,4 & 5,9 \\
\hline 15 a 19 & 33465 & 10 & 12 & 57436 & 3,5 & 4 \\
\hline
\end{tabular}

Fonte: Censo demográfico (BRASIL; IBGE, 1991, 2000).

Em 2000, o índice de analfabetismo da zona rural ainda era superior ao da zona urbana (32\% da população rural e 15,5\% da população urbana), o que permite inferir que a insuficiência de oferta de educação continuou predominante na zona rural. No início da década, o índice de analfabetismo, se calculado da faixa etária de 5 a 9 anos ou de 7 a 9 anos, é semelhante, o que significa a insuficiência de vagas para a educação infantil e primeiro ciclo do ensino fundamental.

Em 2000, houve expressiva redução do analfabetismo entre as crianças de 7 a 9 anos (faixa etária contemplada pelo Fundef), mas as crianças em fase de educação infantil (5 a 6 anos) apresentaram índice de analfabetismo ainda maior, com relação diretamente proporcional ao crescimento demográfico, o que corresponde ao fato da oferta de préescola (nível que não recebia repasses do Fundef) ser insuficiente.

\section{As escolas públicas e privadas}

Em 1991, a rede de escolas da educação básica contava com 407 estabelecimentos de ensino da educação; destes, 25 unidades eram particulares, comportando 6,7\% das matrículas na educação básica. Em 1994, com a estadualização já consolidada, a rede de escolas, outrora federal, passou a ser estadual, havendo, portanto, duas redes de escolas de educação básica pública: estadual e municipal.

$\mathrm{Na}$ análise dos avanços da educação na década de 1990, houve um declínio de crescimento relativo da rede estadual de ensino, embora esta tenha sido objeto dos dois planejamentos de educação. A rede de ensino que mais cresceu foi a particular (128\%), em segundo lugar a municipal (116\%), e a que menos cresceu foi a rede estadual (47\%). Quando acrescentado o triênio seguinte, as mesmas disparidades de crescimento entre a 
rede particular, municipal e estadual se acentuam, com, respectivamente, 276\%, 154\% e 52\%, como se apresenta no Gráfico 1.

Gráfico 1 - Crescimento das redes de escolas do Amapá, de 1991a 2003

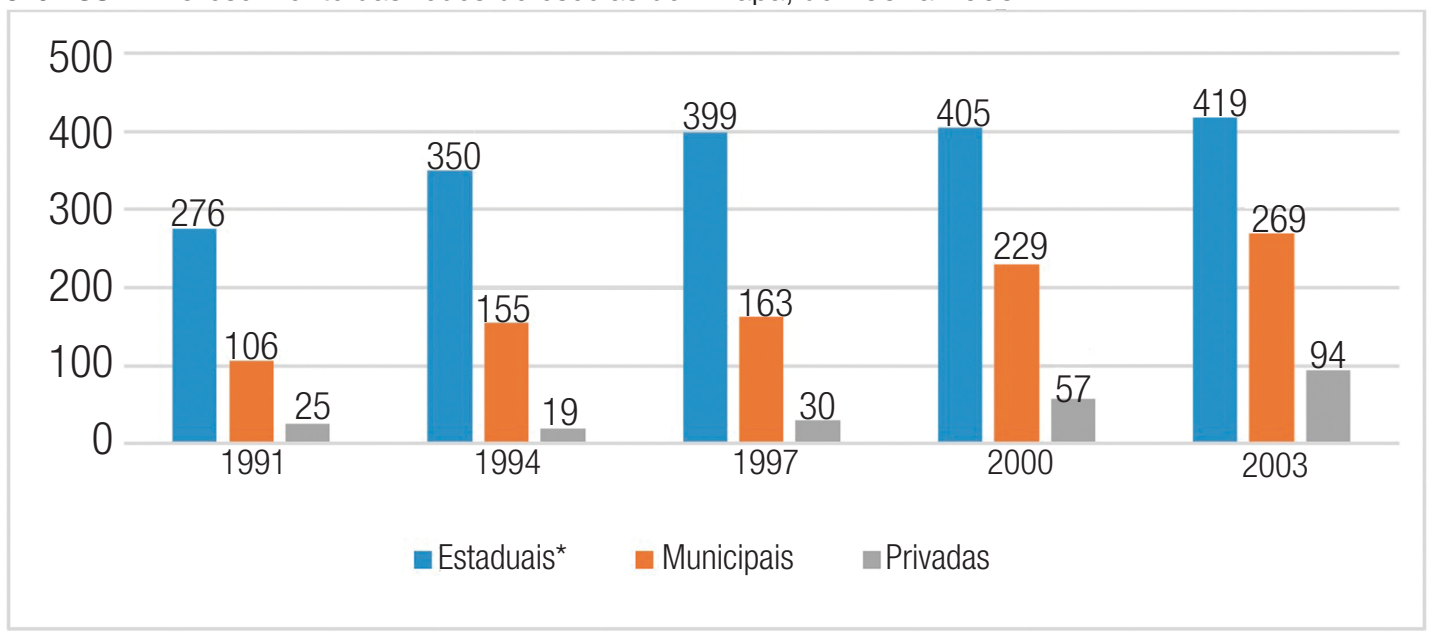

Fonte: Censo escolar (BRASIL; INEP, 1998, 2001, 2003, 2004).

*Nota: em 1991, a rede estadual ainda era federal.

\section{Os profissionais da educação}

Entre 1991 a 1997, o crescimento do quadro de professores foi constante, mas entre 1998 e 1999 apresentou uma redução de mais de trezentos professores. A redução ocorreu na instância administrativa estadual, que compreendia grande número de servidores públicos federais em seu quadro de professores, chegando a 2000 com uma diferença negativa de 225 docentes em relação a 1998.

Entre os possiveis fatores que impulsionaram a redução do quadro de professores da instância administrativa estadual, pode-se citar a promulgação da Lei Federal № 9.468 de 10 de Julho de 1997, que instituiu o Programa de Desligamento Voluntário (PDV) de servidores civis do Poder Executivo Federal - pois muitos destes servidores integravam o quadro estadual do Amapá (BRASIL, 1997). A municipalização do ensino fundamental fomentada pelo Fundef - também pode ter sido um fator de alteração da distribuição de professores entre as redes estadual e municipal no referido período, bem como do menor crescimento da rede estadual de escolas.

Como demonstrado no Gráfico 2, tanto a rede municipal quanto a rede particular de ensino tiveram crescimento constante em seu quadro de professores durante a década de 1990 e mantiveram ritmo similar no triênio seguinte. A retomada do crescimento do quadro de professores estaduais, percebida a partir de 2000, resultou do processo no qual o governo deu posse aos aprovados no concurso público de 1999, cuja contratação havia sido realizada pelo Instituto de Pesquisa e Desenvolvimento em Administração Pública (Ipesap). 
Gráfico 2 - Evolução do quadro de professores da educação básica do Amapá, de 1991 a 2003

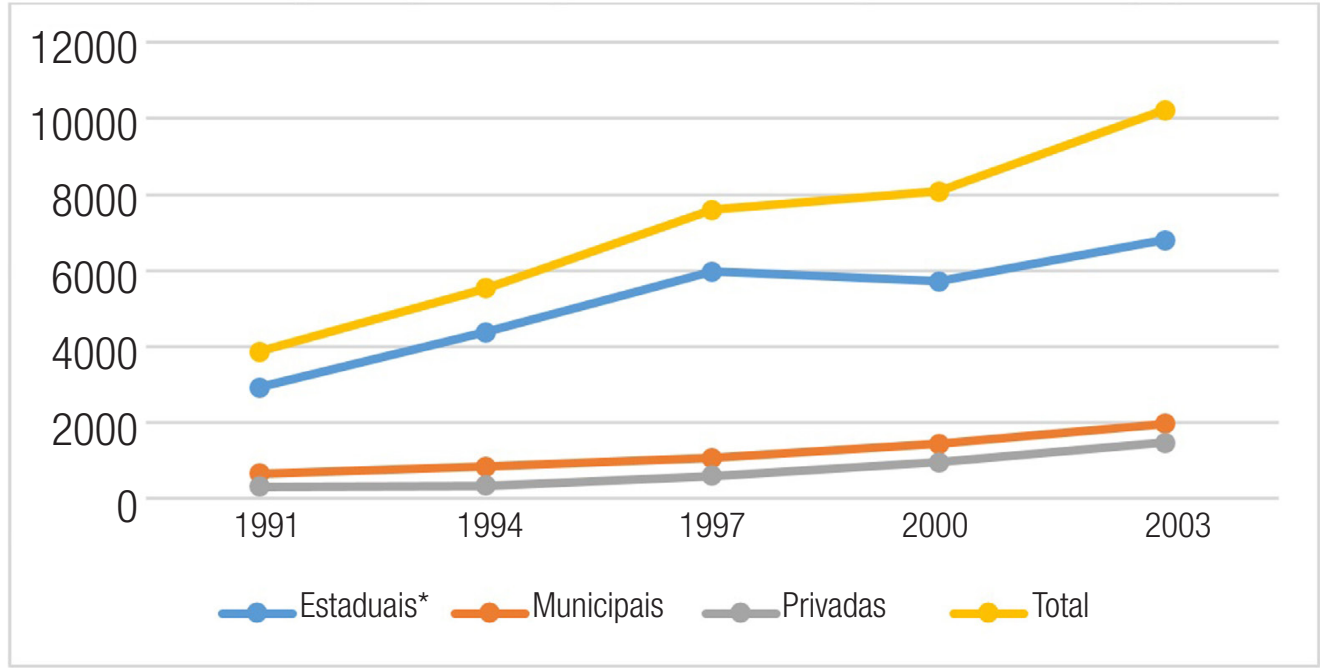

Fonte: Censo escolar (BRASIL; INEP, 1998, 2001, 2003, 2004).

No que tange à formação dos professores, o índice de profissionais com nível superior, no início da década de 1990, era de 32\%, mas caiu para 28\%, no final da década. 0 número de professores com nível médio apresentou aumento real e relativo em toda a década, mantendo-se entre 72 e 70\% do total de profissionais. 0 número de professores leigos (nível fundamental) caiu para 1\%. Como pode ser observado no Gráfico 3, a tendência de crescimento da formação de professores em nível médio apresentou um declínio, entre 1998 e 2000, indício de que a parcela de professores exonerados (demissão voluntária), a partir de 1998, tinha formação majoritariamente de nível médio.

Gráfico 3 - Evolução da formação docente do Amapá, de 1991 a 2003

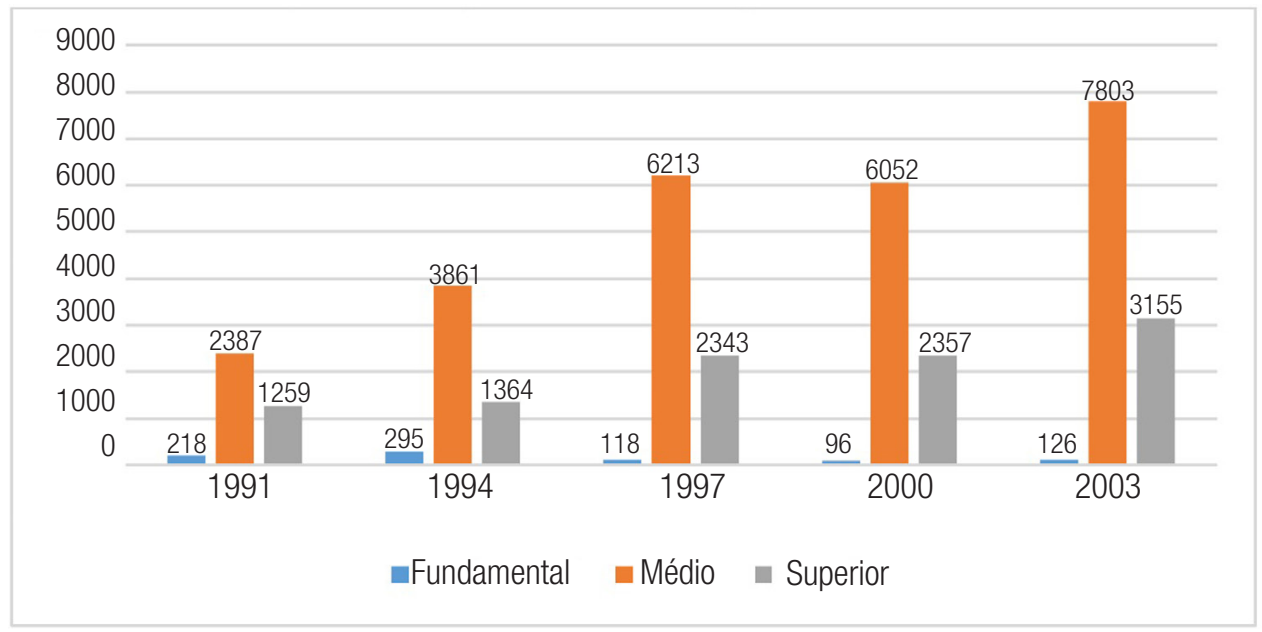

Fonte: Censo escolar (BRASIL; INEP, 1999, 2001, 2003, 2004). 


\section{As matrículas}

No decorrer da década de 1990, o aumento das matrículas da educação básica foi superior ao crescimento populacional: a população apresentou um aumento de 65\%, enquanto as matrículas (rede pública e privada) aumentaram em 116,6\%. No entanto, apesar dos esforços para atender às demandas educacionais da década, estes não foram suficientes, dada a histórica população de analfabetos e um sistema de educação nacional (e por extensão o estadual e municipal) ainda não consolidado, sem um programa para atender às demandas da educação infantil e do ensino médio, bem como atender ao contingente de adultos que não tiveram acesso à educação na fase adequada.

Prorrogando-se mais um triênio até 2003, o crescimento foi de 130\%. Como mostra o Gráfico 4, houve um constante aumento no número de matrículas, com o maior quantitativo no período de 1997 a 2000, e o menor entre 2000 e 2003, o que caracteriza uma estagnação no final da década. Em termos percentuais, na análise dos triênios, a maior taxa de crescimento (47,8\%) ocorreu no período de 1994 a 1997 e a menor (6\%) no período 2000 a $2003 .^{7}$

Gráfico 4 - Crescimento do acesso à educação básica no Amapá, de 1991 a 2003

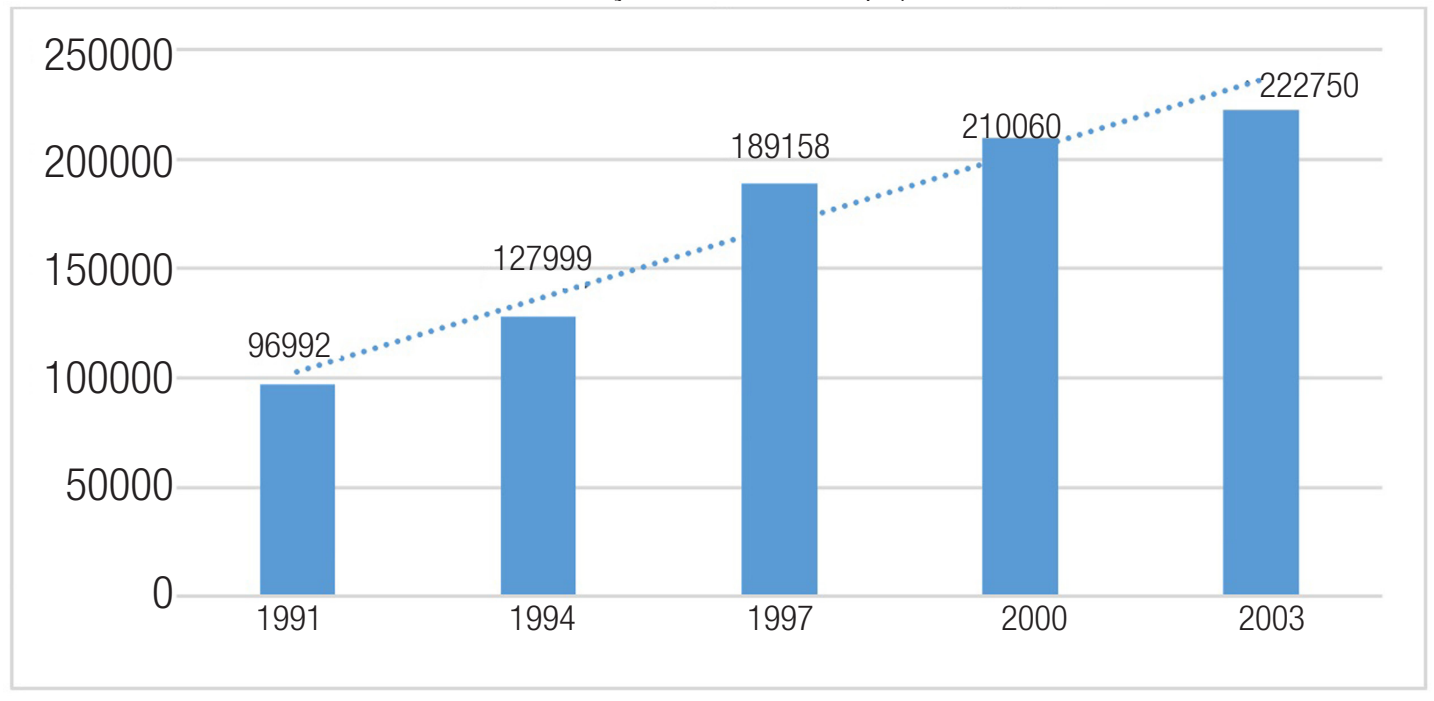

Fonte: Censo escolar (BRASIL; INEP, 1998, 2001, 2003, 2004).

A comparação dos dados nacionais e estaduais demonstra que o Amapá apresentou crescimento do acesso à educação básica bem acima dos índices nacionais, como evidenciado na Tabela 3. Tanto em nível estadual quanto nacional, o maior crescimento foi registrado entre 1994 e 1997, embora o período de 1991 a 1994 se apresente expressivo, seguido do período de 1997 a 2000, quando o crescimento ocorreu em ritmo inferior ao início da década.

7- 0 índice de crescimento do triênio 1994-1997 seria reduzido a 35\% se as matrículas no supletivo e educação especial constassem no censo de 1994. Educação especial e EJA (antigo supletivo) só aparecem no censo escolar de 1997. Em 1996, aparecem 12.089 matrículas do ensino supletivo. 
Tabela 3 - Crescimento percentual das matrículas na educação básica -AP/BR, de 1991 a 2003, por triênios

\begin{tabular}{c|cc}
\hline Periodo & Amapá (\%) & Brasil (\%) \\
\hline 1991 a 1994 & 32 & 11 \\
\hline 1994 a 1997 & 48 & 17 \\
\hline 1997 a 2000 & 11 & 3 \\
\hline 2000 a 2003 & 6 & 45 \\
\hline 1991 a 2003 & 130 & 3 \\
\hline
\end{tabular}

Fonte: Censo escolar (BRASIL; INEP, 1998, 2001, 2003, 2004).

No que tange ao número de alunos/matrículas por rede de escolas, embora a rede estadual apresentasse o maior número de alunos, no decorrer da década de 1990, seu crescimento ocorreu em menor grau do que as redes municipais e privadas, sendo esta última a que apresentou o maior índice de crescimento da década - 177\%. A rede municipal aumentou o seu número de matrículas em 141\% e a estadual em 107\%.

Como assinalado no Gráfico 5, o maior número de matrículas na rede estadual ocorreu no triênio 1994-1997, quando então apresentou um arrefecimento no ritmo de crescimento: apenas 3\% no triênio 1997-2000. No triênio seguinte, teve redução no número de matrículas, provavelmente em razão do avanço da iniciativa privada e do processo de municipalização da educação infantil e do ensino fundamental, desde a implantação do Fundef.

Gráfico 5 - Evolução das matrículas por rede de escolas do Amapá, de 1991 a 2003

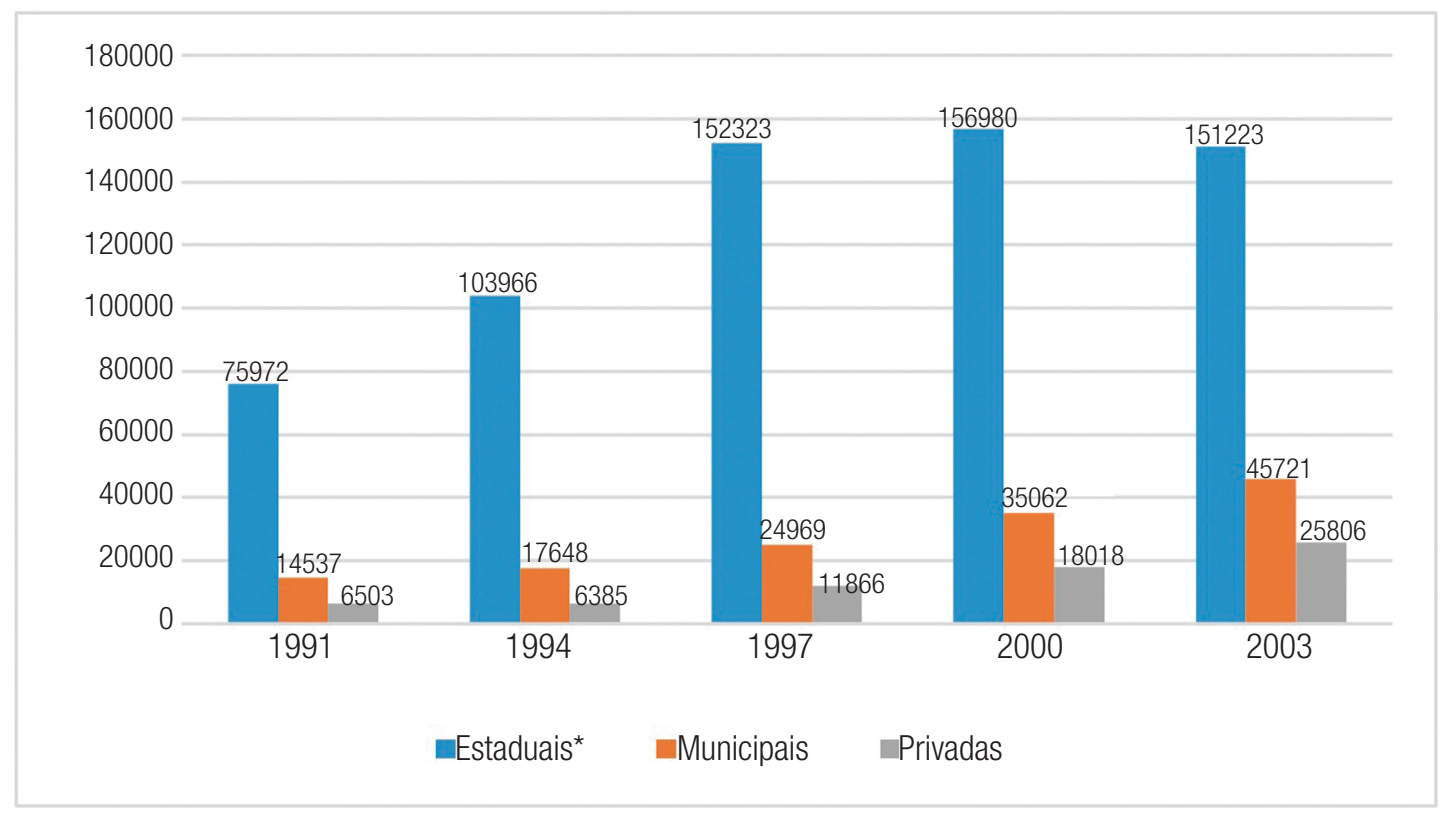

Fonte: Censo escolar (BRASIL; INEP, 1998, 2001, 2003, 2004).

*Nota: em 1991, a rede estadual ainda era federal. 
A iniciativa privada, embora abarcasse pouco mais de $11 \%$ da população de alunos matriculados em 2003, apresentou um crescimento de 297\%, entre 1991 e 2003, enquanto o ensino público cresceu 117\% no mesmo período, situação inversa ao ocorrido em nível nacional, no qual o crescimento relativo foi menor e inverso no que se refere ao público e privado, como demonstrado na Tabela 4.

Tabela 4 -Aumento relativo das matrículas nas redes de educação pública e privada do Amapá, de 1991 a 2003

\begin{tabular}{|c|c|c|c|c|}
\hline & \multicolumn{2}{|c|}{$1991-2000(\%)$} & \multicolumn{2}{|c|}{$1991-2003(\%)$} \\
\hline & Pública & Particular & Pública & Particular \\
\hline Brasil & 47 & 2 & 49,6 & 16,5 \\
\hline Amapá & 112 & 177 & 117 & 297 \\
\hline
\end{tabular}

Fonte: Censo escolar (BRASIL; INEP, 2001, 2003, 2004).

0 ensino fundamental já apresentava maiores índices de oferta de educação (matrículas) no início da década de 1990, tornou-se o foco do Plano Decenal de Educação para Todos, em 1993 (BRASIL; MEC, 1993), e, em 1997, recebeu novos mecanismos para operacionalização da meta de universalização através do Fundef, que começou a vigorar, em 1998. Por conseguinte, no decorrer da década, o referido nível de ensino apresentou crescimento superior aos demais níveis, desencadeando um gargalo na educação - o ensino médio.

No triênio 1997-2000, percebe-se um declínio nas matrículas da educação infantil, enquanto o ensino médio e a EJA continuaram a crescer, a EJA com um maior contingente de matrículas do que o ensino médio, quando então teve declínio nas matrículas chegando a 2003 com quantitativo similar ao de 1997. No triênio subsequente à década de 1990, o ensino médio, continuou crescendo, a educação especial, porém, apenas no censo de 1997 apresentou número de matrículas acima de mil, como se demonstra no Gráfico 6.

Gráfico 6 - Evolução das matrículas da educação básica por nível e modalidade de ensino do Amapá, de 1991 a 2003

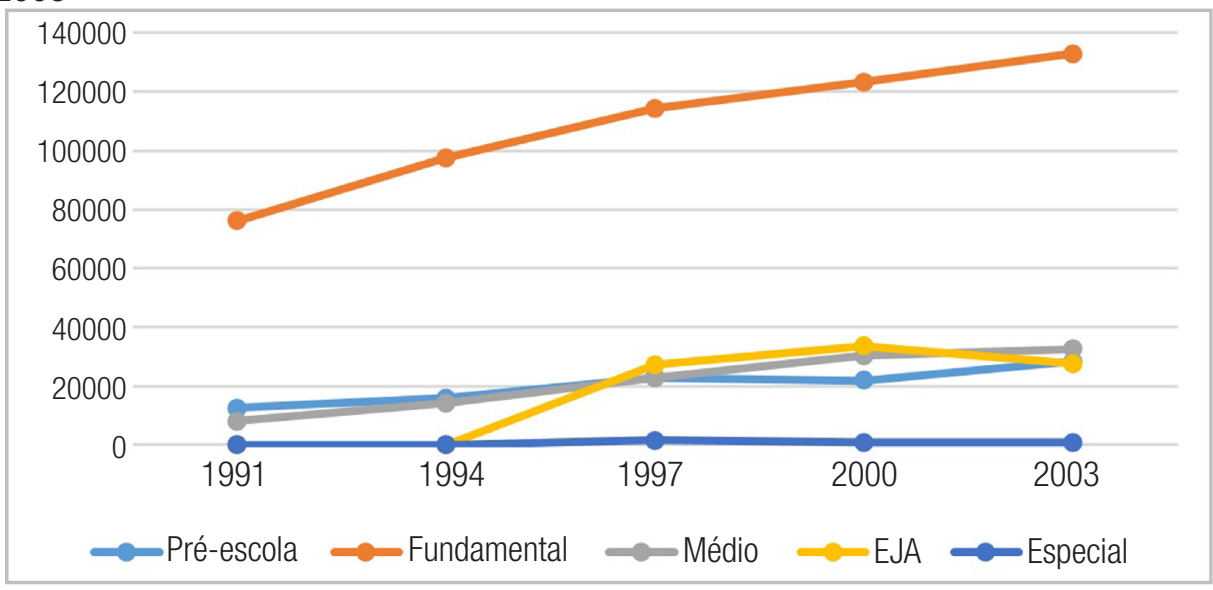

Fonte: Censo escolar (BRASIL; INEP, 1998, 2001, 2003, 2004). 


\section{0 rendimento da educação básica}

Dos 96.992 alunos matriculados na educação básica do Amapá, em 1991, apenas 60\% obteve êxito (aprovação), portanto 40\% das matrículas resultaram em reprovação e evasão. Os índices de aprovação apresentaram tendência crescente nos triênios seguintes chegando a 64\%, em 1994, 69\%, em 1997, 73\%, em 2000, e 76\%, em 2003, como pode ser observado no Gráfico 7.

Gráfico 7- Rendimento da educação básica no Amapá, de 1991 a 2003

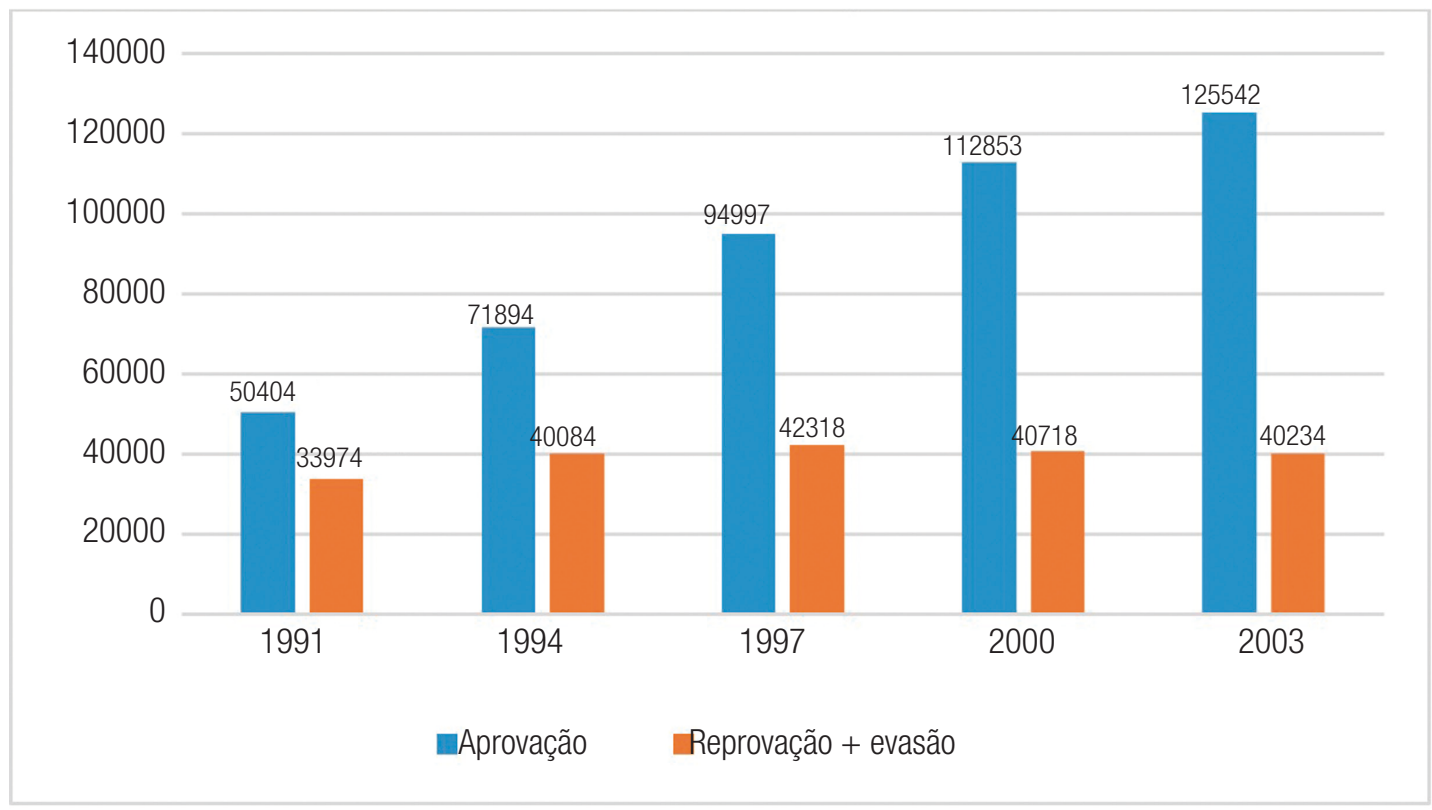

Fonte: Censo escolar (BRASIL; INEP, 1998, 2001, 2003, 2004).

Apesar do expressivo aumento de aprovações, os índices de sucesso escolar no Amapá permaneceram abaixo dos índices nacionais, como demonstrado na Tabela 5.

Tabela 5 - Índices de aprovação na educação básica - AP/BR, de 1991 a 2003

\begin{tabular}{cccccc}
\hline Ano & $\vdots$ & Brasil (\%) & Amapá (\%) \\
\hline 1991 & $\vdots$ & 64 & 60 \\
\hline 1994 & $\vdots$ & 67 & 64 \\
\hline 1997 & $\vdots$ & 77 & 69 \\
\hline 2000 & $\vdots$ & 77 & 73 \\
\hline 2003 & $\vdots$ & 78 & 76 \\
\hline
\end{tabular}

Fonte: Censo escolar (BRASIL; INEP, 1998, 2001, 2003, 2004). 
Na análise do fluxo de estudo dos alunos no Amapá em onze anos - duração normal da educação básica no Brasil naquele período - foi constatado que apenas 31\% dos alunos que ingressaram no ensino fundamental, em 1991, concluíram o $3^{\circ}$ ano do ensino médio, em 2001, índice semelhante ao nacional. Quanto à educação especial e à EJA, uma vez que os dados do início da década não estão disponíveis, não se pode inferir, com precisão, sua evolução na década em análise. No entanto, como se demonstrou no Gráfico 6, a EJA apresentou tendência decrescente, no final da década, e a educação infantil apresentou números inexpressivos, durante os triênios analisados, com tendência decrescente.

0 Quadro 1 apresenta, em síntese, os resultados dos indicadores supracitados. A sua leitura em linha permite observar o desempenho dos indicadores no período em questão (1991-2003).

Quadro 1 - Síntese dos avanços da educação básica no Amapá (1991-2003)

\begin{tabular}{|c|c|c|c|c|}
\hline \multicolumn{2}{|c|}{ Avanços da educação básica } & 1991 & 2000 & 2003 \\
\hline \multicolumn{2}{|c|}{ População alfabetizada com 5 anos de idade ou mais (\%) } & 76 & 83 & - \\
\hline \multirow{2}{*}{ Unidades escolares } & Rede pública & 382 & 634 & 688 \\
\hline & Rede privada & 25 & 57 & 94 \\
\hline \multicolumn{2}{|c|}{ Profissionais da educação } & 3864 & 8081 & 10224 \\
\hline \multirow{3}{*}{$\begin{array}{l}\text { Formação dos profissionais da } \\
\text { educação }\end{array}$} & Nível fundamental & 218 & 96 & 126 \\
\hline & Nível médio & 2387 & 6052 & 7803 \\
\hline & Nível superior & 1259 & 2357 & 3155 \\
\hline \multirow{2}{*}{ Matrículas } & Rede pública & 90488 & 192042 & 196944 \\
\hline & Rede privada & 6503 & 18018 & 25806 \\
\hline \multirow{2}{*}{ Rendimento (\%) } & Aprovação & 60 & 73 & 76 \\
\hline & Reprovação e evasão & 40 & 27 & 24 \\
\hline
\end{tabular}

Fonte: Censo escolar (BRASIL; INEP, 2001, 2003, 2004).

\section{Considerações finais}

A análise das propostas e resultados da educação no Amapá, na década de 1990 e do triênio seguinte, até 2003, assinalou que houve crescimento quantitativo na educação básica, no que tange ao número de escolas, de profissionais da educação e de matrículas. Contudo, os resultados foram insatisfatórios, uma vez que a meta de erradicar o analfabetismo e universalizar o ensino fundamental não foi plenamente atingida. Ademais, ainda se destaca a situação precária da educação infantil e o ensino médio, este um gargalo para a década seguinte e talvez para um período indefinido.

Considerando que a educação e o desenvolvimento econômico são interdependentes para o desenvolvimento pleno, os dados apresentados do Índice de Gini, importante indicador da concentração da renda e, por conseguinte, um medidor da desigualdade, 
apontam possíveis fatores impeditivos do desenvolvimento pleno da educação no Amapá: a pobreza e a necessidade de subsistência em detrimento da educação nas camadas populares, como alertado no Plano Decenal de Educação do Estado do Amapá.

Ao final desta análise, conclui-se que os planejamentos e as políticas de educação do novo estado apresentaram pouca consistência operacional e descontinuidade de projetos, esta última decorrente, entre outros fatores, da interferência política partidária no estado. Em outras palavras, o Amapá seguiu o ciclo de debates e propostas nacionais e a assinatura de documentos, mas não empreendeu os esforços necessários à educação para todos proposta na Declaração Mundial de Educação para Todos, pois grande parte do que foi planejado não foi operacionalizado ou alcançado, apontando para um fragilidade institucional, assinalada por diversos autores.

Parafraseando Leonelli (2000, p. 214), a proposta de educação para "vencer a resistência conservadora com a beleza das ideias" infelizmente não se distanciou da etapa da beleza das ideias.

\section{Referências}

ABRANTES, Joselito Santos. (Des)envolvimento Local em Regiões Periféricas do Capitalismo: limites e perspectivas no caso do estado do Amapá (1966 a 2006). Rio de Janeiro: Garamond, 2014.

AMAPÁ. Governo do Estado do Amapá. Amapá programa de desenvolvimento sustentável. Macapá: GEA, 1995.

AMAPÁ. Governo do Estado do Amapá. Bases do desenvolvimento sustentável: coletânea de textos. Macapá: GEA, 1999.

AMAPÁ. Secretaria de Estado da Educação. Diretrizes curriculares da educação escolar básica do estado do Amapá. Macapá: Mimeo, 2002.

AMAPÁ. Secretaria de Estado da Educação. Plano decenal de educação do estado do Amapá. Macapá: Mimeo, 1993.

BOLLMANN, Maria da Graça Nóbrega. Revendo o plano nacional de educação: proposta da sociedade brasileira. Educação \& Sociedade, Campinas, v. 31, n. 112, p. 657-676, jul./set. 2010.

BRASIL. Lei de Diretrizes e Base da Educação Nacional. Brasília, DF: MEC, 2010.

BRASIL. LEI No 9.468, de 10 de julho de 1997. Institui o Programa de Desligamento Voluntário de servidores civis do Poder Executivo Federal e dá outras providências. Brasília, DF, 1997. Disponível em: <http://www. planalto.gov.br/ccivil_03/leis/L9468.htm>. Acesso em: 20 de jan. de 2019.

BRASIL. Lei $\mathrm{N}^{\circ}$ 10.172, de 9 de janeiro de 2001. Aprova o Plano Nacional de Educação e dá outras providências. Brasília, DF: MEC, 2001. 
BRASIL. IBGE. Instituto Brasileiro de Geografia e Estatística. Censo demográfico 1991: características gerais da população e instrução: resultados da amostra. Rio de Janeiro: IBGE, 1991.

BRASIL. IBGE. Instituto Brasileiro de Geografia e Estatística. Censo demográfico 2000: características gerais da população e instrução: resultados da amostra. Rio de Janeiro: IBGE, 2000.BRASIL. INEP. Instituto Nacional de Estudos e Pesquisas Educacionais. Sinopse estatística da educação básica: censo escolar 1997. Brasília, DF: Inep, 1998.

BRASIL. INEP. Instituto Nacional de Estudos e Pesquisas Educacionais. Sinopse estatística da educação básica: censo escolar 1998. Brasília, DF: Inep, 1999.

BRASIL. INEP. Instituto Nacional de Estudos e Pesquisas Educacionais. Sinopse estatística da educação básica: censo escolar 1999. Brasília, DF: Inep, 2000.

BRASIL. INEP. Instituto Nacional de Estudos e Pesquisas Educacionais. Sinopse estatística da educação básica: censo escolar 2000. Brasília, DF: Inep, 2001.

BRASIL. INEP. Instituto Nacional de Estudos e Pesquisas Educacionais. Sinopse estatística da educação básica: censo escolar 1991-1995. Brasília, DF: Inep, 2003.

BRASIL. INEP. Instituto Nacional de Estudos e Pesquisas Educacionais. Sinopse estatística da educação básica: censo escolar 2003. Brasília, DF: Inep, 2004.

BRASIL. INEP. Instituto Nacional de Estudos e Pesquisas Educacionais. MEC. Ministério da Educação. Indicadores da qualidade na educação. São Paulo: Ação Educativa, 2004. Disponível em: <http://www. portal.mec.gov.br>. Acesso em: 3 maio 2018.

BRASIL. MEC. Ministério da Educação. Fundef: manual de orientação. Brasília, DF: MEC, 2004. Disponível em: <http://mecsrv04.mec.gov.br/sef/fundef/pdf/manual2.pdf>. Acesso em: 12 jan. 2018.

BRASIL. MEC. Ministério da Educação. Plano Decenal de Educação para Todos. Brasília, DF: MEC, 1993. Versão acrescida. $136 \mathrm{p}$.

BRASIL. MMA. Ministério do Meio Ambiente. Agenda 21 Global. Brasília, DF: MMA, 1992. Disponível em: $<$ http://www.mma.gov.br/responsabilidade-socioambiental/agenda-21/agenda-21-global>. Acesso em: 02 maio 2019.

BRASIL. MS. Ministério da Saúde. Datasus. Índice de Gini da renda domiciliar per capita segundo região, UF e região metropolitana/período: 1991-2000. In: BRASIL. Datasus. Índice de Gini da renda domiciliar per capita - Brasil. Brasília, DF: MS, 1991. Disponível em: <http://tabnet.datasus.gov.br/cgi/ibge/censo/cnv/ giniuf.def>. Acesso em: 21 abr. 2018.

BRASIL. MS. Ministério da Saúde. Datasus. Índice de Gini da renda domiciliar per capita segundo região, UF e região metropolitana/período: 1991-2000. In: BRASIL. Datasus. Índice de Gini da renda domiciliar per capita - Brasil. Brasília, DF: MS, 2000. Disponível em: <http://tabnet.datasus.gov.br/cgi/ibge/censo/cnv/ giniuf.def>. Acesso em: 21 abr. 2018. 
CARNEIRO, Moaci Alves. 0 nó do ensino médio. 3. ed. Petrópolis: Vozes, 2012.

CHELALA, Charles. A magnitude do estado na socioeconomia amapaense. 2008. 178 f. Dissertação (Mestrado em Desenvolvimento Regional) - Universidade Federal do Amapá: Macapá, 2008.

COELHO, Vera Schattan Ruas Pereira. Abordagens qualitativas e quantitativas na avaliação de políticas públicas. In: CEBRAP. Métodos de pesquisa em ciências sociais: bloco quantitativo. São Paulo: Sesc: Cebrap, 2016. p.I79-99.

FERREIRA, Norma Iracema de Barros. Política e educação no Amapá: de território a Estado. 2005. Tese (Doutorado em Educação) - Universidade Estadual Paulista Júlio de Mesquita Filho, Araraquara, 2005.

FURTAD0, Celso. Os desafios da nova geração. Revista de Economia Política, São Paulo, v. 24, n. 4 (96), p. 483-48, out./dez. 2004.

GAD0TTI, Moacir. Da palavra à ação. In: BRASIL. MEC. Ministério da Educação. Educação para Todos: avaliação da década. Brasília, DF: MEC/INEP, 2000. p. 27-32.

GHIRALDELLI JÚNIOR, Paulo. História da educação. São Paulo: Cortez, 1990.

GIL, Antônio Carlos. Métodos e técnicas de pesquisa social. São Paulo: Atlas, 1989.

HERMIDA AVEIRO, Jorge Fernando. A reforma educacional no Brasil (1988-2001): processos legislativos, projetos em conflito e sujeitos históricos. 2002. 355 f. Tese (Doutorado) -Universidade Estadual de Campinas, Campinas, 2002. Disponível em: <http://www.repositorio.unicamp.br/handle/REPOSIP/251752>. Acesso em: 2 jan. 2018.

LEONELLI, Domingos. Uma sustentável revolução na floresta. São Paulo: Viramundo, 2000.

MOULIN, Nilson (Org.). Amapá: um norte para o Brasil. São Paulo: Cortez, 2000.

SAVIANI, Dermeval. História das ideias pedagógicas no Brasil. Campinas: Autores Associados, 2007.

SAVIANI, Dermeval. Política e educação no Brasil: o papel do Congresso Nacional na legislação do ensino. 5. ed. Campinas: Autores Associados, 2002.

WOLFFENBÜTTEL, Andréa. Indicadores. Desafios do Desenvolvimento, Brasília, DF, v. 1. n. 4, p. 80-82, 1 nov. 2004. 
Antonia Deusa Sá é licenciada em ciências sociais e mestre em desenvolvimento regional pela Universidade Federal do Amapá. Professora de sociologia no ensino médio na rede estadual de ensino do Amapá. Professora de inglês em cursos livres.

José Francisco de Carvalho Ferreira é doutor em geografia e planeamento territorial, com estágio pós-doutoral em desenvolvimento regional. Professor de geografia e nos mestrados em desenvolvimento regional e geografia da Unifap. Colaborador do CICS-NOVA, da FCSH/ UNL, Lisboa, Portugal. 